\title{
Erratum to: Evolution and systematics of Green Bush-crickets (Orthoptera: Tettigoniidae: Tettigonia) in the Western Palaearctic: testing concordance between molecular, acoustic, and morphological data
}

Beata Grzywacz $^{1}$ - Klaus-Gerhard Heller ${ }^{2}$ - Elżbieta Warchałowska-Śliwa ${ }^{1}$.

Tatyana V. Karamysheva ${ }^{3}$ - Dragan P. Chobanov ${ }^{4}$

Published online: 14 January 2017

(C) Gesellschaft für Biologische Systematik 2017

Erratum to: Org Divers Evol

DOI 10.1007/s13127-016-0313-3

Table 1 contains a mistake. The haplotypes tct 1 and tct 3 should be T. caudata (Charpentier, 1842) instead of T. cantans (Fuessly, 1775).

The online version of the original article can be found at http://dx.doi. org/10.1007/s13127-016-0313-3.

Beata Grzywacz

grzywacz@isez.pan.krakow.pl

1 Institute of Systematics and Evolution of Animals, Polish Academy of Sciences, Sławkowska 17, 31-016 Krakow, Poland

2 Grillenstieg 18, 39120 Magdeburg, Germany

3 Institute of Cytology and Genetics of the Siberian Branch of the Russian Academy of Sciences, Novosibirsk, Russia

4 Institute of Biodiversity and Ecosystem Research, Bulgarian Academy of Sciences, 1 Tsar Osvoboditel Boul, 1000 Sofia, Bulgaria 